\title{
Titanium Oxide Nanotube Surface Topography and MicroRNA-488 Contribute to Modulating Osteogenesis
}

\author{
Yeon-Ho Kang, ${ }^{1}$ Bohm Choi, ${ }^{2}$ Chihyun Ahn, ${ }^{1}$ Seunghan $0{ }^{3}{ }^{3}$ \\ Myeung Soo Lee, ${ }^{4}$ and Eun-Jung Jin ${ }^{1}$ \\ ${ }^{1}$ Department of Biological Sciences, College of Natural Sciences, Wonkwang University, Iksan, Chungbuk 570-749, Republic of Korea \\ ${ }^{2}$ Department of Dentistry, Uijeongbu St. Mary's Hospital, The Catholic University of Korea, Uijeongbu, \\ Gyeonggi 480-717, Republic of Korea \\ ${ }^{3}$ Department of Dental Biomaterials, College of Dentistry, Wonkwang University, Iksan, Chunbuk 570-749, Republic of Korea \\ ${ }^{4}$ Department of Internal Medicine, Division of Rheumatology, Wonkwang University School of Medicine, Iksan, \\ Chunbuk 570-749, Republic of Korea
}

Correspondence should be addressed to Myeung Soo Lee; ckhlms@wonkwang.ac.kr and Eun-Jung Jin; jineunjung@wku.ac.kr

Received 13 February 2014; Accepted 31 March 2014; Published 22 April 2014

Academic Editor: Young-Bum Park

Copyright (C) 2014 Yeon-Ho Kang et al. This is an open access article distributed under the Creative Commons Attribution License, which permits unrestricted use, distribution, and reproduction in any medium, provided the original work is properly cited.

Understanding the biocomplexity of cell behavior in relation to the topographical characteristics of implants is essential for successful osseointegration with good longevity and minimum failure. Here, we investigated whether culture on titanium oxide $\left(\mathrm{TiO}_{2}\right)$ nanotubes of various diameters could affect the behavior and differentiation of MC3T3-E1 cells. Among the tested nanotubes, those of $50 \mathrm{~nm}$ in diameter were found to trigger the expression of the osteoblast-specific transcription factors, sp7 and Dlx5, and upregulate the expression of alkaline phosphatase (ALP). Here, we report that miR-488 was significantly induced in osteoblasts cultured on $50 \mathrm{~nm}$ nanotubes and continued to increase with the progression of osteoblast differentiation. Furthermore, downregulation of miR-488 suppressed the expression levels of ALP and matrix metalloprotease-2 (MMP-2). This suppression of ALP transcription was overcome by treatment with the MMP-2 activator, bafilomycin A1. Collectively, these results suggest that $50 \mathrm{~nm}$ is the optimum $\mathrm{TiO}_{2}$ nanotube diameter for implants, and that modulation of miR- 488 can change the differentiation activity of cells on $\mathrm{TiO}_{2}$ nanotubes. This emphasizes that we must fully understand the physicochemical properties of $\mathrm{TiO}_{2}$ nanotubes and the endogenous biomolecules that interact with such surfaces, in order to fully support their clinical application.

\section{Introduction}

Accumulating experimental evidence suggests that nanoscale topography is an important factor for cellular recognition of the biological microenvironment and biomimetic materials used for vascular grafts, stents, and bone implants $[1,2]$. Titanium (Ti) and its alloys have been widely used as implantation materials, as they provide direct physical bonding with the adjacent bone surface in orthopedic and dental surgery. The low success rate of using machined surfaces, such as those first tested as dental implants in 1965, has long indicated that the materials and particle sizes of implant surfaces are critical to the initial osseointegration and success of implants [3]. Although the current success rate is very high, implants still occasionally loosen and fail due to incomplete osseointegration between the implantation materials and the surrounding bone [3].

Several studies have suggested that some cells can show cell-type-specific behaviors and activities on $\mathrm{TiO}_{2}$ nanotubes. For example, mesenchymal stem cells showed enhanced activity on anatase-phase nanotubes $(70-100 \mathrm{~nm}$ diameter), and proliferation of smooth muscle cells was enhanced on $\mathrm{TiO}_{2}$ [4]. Furthermore, Webster et al. [5] reported that osteoblasts showed significantly greater adhesion to a nanophase surface compared to conventional aluminum and titanium surfaces.

MicroRNAs (miRNAs) are short (18-25 nucleotides) noncoding RNAs that posttranscriptionally regulate gene expression by recognizing binding sites in the $3^{\prime}$ - untranslated 
regions ( $3^{\prime}$-UTRs) of target genes [6, 7]. Growing evidence suggests that miRNAs regulate various developmental and homeostatic events in vertebrates and invertebrates. For example, miRNAs have been implicated in osteoblast differentiation [8] and osteogenesis. miR-206 is expressed in the osteoblastic cell lineage, where its expression gradually decreases in parallel with osteoblast differentiation [9]. The modulation of miR-206 expression in osteoblasts markedly affects their differentiation potential by altering the accumulation of connexin 43, and the osteoblast-specific expression of miR-206 in vivo triggers severe bone loss by impairing osteoblast differentiation [10]. miR-29 and miR-133 also appear to be important for osteoblast differentiation [11, 12]: miR-29 increases during the progression of osteoblastic differentiation in primary cultures of murine calvarial osteoblasts [13], while miR-133 seems to negatively regulate the differentiation of osteoblasts [14]. Recently, our laboratory demonstrated that miR-488 contributes to the regulation of matrix metalloprotease (MMP)-2 [13]. Since MMP-2 is thought to control homeostatic and morphogenetic events during osteogenic differentiation [15], we speculate that miR488 is involved in the formation of bone [14, 16].

Here, we studied the in vitro behavior of osteoblast cells cultured on vertically aligned $\mathrm{TiO}_{2}$ nanotubes of different diameters. We investigated the effect of such nanostructures on osteoblast cell morphology and the kinetics of cell proliferation, examined cell responses on nanotubes versus plastic polypyrene layers, and tested for differential expression of miR-488.

\section{Experimental Section}

2.1. Cell Culture and Differentiation. The differentiation of MC3T3-E1 cells (ATCC, Rockville, MD) was induced by incubation in differentiation medium (growth medium containing $50 \mu \mathrm{g} / \mathrm{mL}$ ascorbic acid and $10 \mathrm{mM} \mathrm{2-}$ glycerophosphate). The medium was changed every 2 to 3 days. Differentiation was assessed by alizarin red staining. Briefly, differentiated cell layers were washed with phosphate buffered saline (PBS) and then fixed for 15 min with neutral formalin (10\% formaldehyde in PBS). The fixation solution was removed and the cells were incubated in distilled water for $15 \mathrm{~min}$ and then with $1 \%$ alizarin red solution for $5 \mathrm{~min}$. The staining solution was removed, the cells were rinsed three times with water, and the stained cultures were kept in distilled water for microscopic examination.

2.2. $\mathrm{TiO}_{2}$ Nanotube Preparation. Ti sheets (thickness, $250 \mu \mathrm{m}$; purity, 99.5\%; Alfa-Aesar, Ward Hill, MA) were sequentially cleaned with acetone, $70 \%$ ethanol, and water. Cleaned specimens were anodized with hydrofluoric acid ( 0.5 w/v\%; purity, $48 \%$; EM-Science, Gardena, CA) at $20 \mathrm{~V}$ for 30 minutes. The prepared $\mathrm{TiO}_{2}$ nanotube specimens were washed under running water for 30 seconds, dried overnight at $80^{\circ} \mathrm{C}$, and heat-treated for 2 hours at $500^{\circ} \mathrm{C}$. Heat-treated specimens were cut into pieces $(1.27 \times 1.27)$ and then sterilized in an autoclave.

2.3. Cell Culture on $\mathrm{TiO}_{2}$ Nanotubes. MC3T3-E1 cells were incubated in differentiation medium as described above and placed on the $\mathrm{TiO}_{2}$ nanotubes. After 2 days, biochemical and cellular analyses (see below) were performed.

2.4. Immunocytochemistry. Cells grown on cover slips were washed three times with PBS and then fixed and permeabilized as described above. For actin staining, samples were stained with Alexa488-phalloidin (Molecular Probes, Eugene, OR) prepared in PBS containing $1 \%(\mathrm{v} / \mathrm{v})$ bovine serum albumin for $1 \mathrm{~h}$ at room temperature in a lightproof box. The samples were then washed three times with water, mounted with Gel/Mount (Biomedia, Foster City, CA), and examined under a confocal microscope (MRC 1024/ES, BioRad, CA).

2.5. Real-Time Quantitative RT-PCR of miRNA and $m R N A$ Expression Levels. The expression levels of various mRNAs were quantified using the appropriate real-time quantitative polymerase chain reaction- (RT-PCR-) based gene expression assay kits (Applied Biosystems, Grand Island, NY). The results were normalized with respect to the expression of GAPDH. The following primers were utilized: GAPDH, forward (Fw) $5^{\prime}$-tgtccgtcgtggatctgac- $3^{\prime}$ and reverse (Rv) $5^{\prime}$-cctgcttcaccaccttcttg- $3^{\prime}$; ALP, Fw $5^{\prime}$ atctcagggcaatgaggtac $-3^{\prime}$ and $\mathrm{Rv} 5^{\prime}$-cacccgagtggtagtcacaa- $3^{\prime}$; $s p 7$, Fw $5^{\prime}$-gagaagaagcccattcaca- $3^{\prime}$ and Rv $5^{\prime}$-gcaggcaggtgaacttcttc- $3^{\prime}$; Dlx5, Fw $5^{\prime}$-ccagccagagaaagaagtgg- $3^{\prime}$ and Rv $5^{\prime}$ tcacctgtgtttgcgtcagt- $3^{\prime}$; and MMP-2, FW $5^{\prime}$-atgccatccctgataacctg- $3^{\prime}$ and $\operatorname{Rv} 5^{\prime}$-tgatgcttccaacttcacg- $3^{\prime}$.

2.6. Synthesis and Transfection of the PNA-Based miRNA Inhibitor. The FAM-conjugated PNA-based ASOs, which contained an O-linker at the N-terminus of the PNA to improve solubility, were purchased from Panagene (Korea). A scrambled PNA-based ASO was used as a negative control. The PNA-based ASO (PNA488: UUGAAAGGCUAUUUCUUGGUC; $200 \mathrm{nM}$ ) was electroporated into cells using a square-wave generator (BTX-830; Gentronics, San Diego, CA) with 200 square-wave pulses of 20 msec each.

\section{Results and Discussion}

Recent studies have revealed that miRNAs can help regulate osteoblast differentiation [10,13] and osteogenesis [17]. Many miRNAs appear to inhibit osteogenesis by repressing osteoblastic genes [18]. Hassan et al. [19] identified a novel miRNA mechanism through which BMP-2 promotes osteoblastogenesis. miR-29a and miR-29c inhibit the expression of Dlx5 in preosteoblasts during osteogenesis [10] and miR-125b inhibits osteoblastic proliferation by targeting the ErbB2 receptor tyrosine kinase [20]. We previously showed that miR-488 is involved in regulating MMP-2 during endochondral ossification [13], indicating that miR-488 is involved in bone formation.

Here, we first examined the expression of miR-488 during osteoblast differentiation and found that it was two-fold higher in differentiated osteoblasts, as shown by alizarin red $\mathrm{S}$ staining, which is used to monitor calcium accumulation (i.e., mineralization) in the ECM (Figure 1(a)). To further examine 


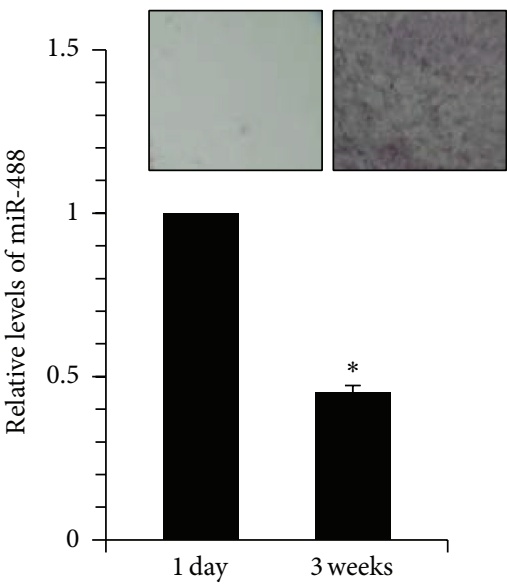

(a)

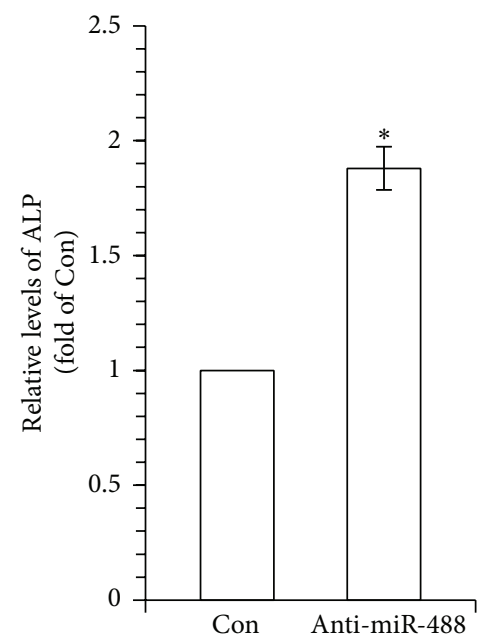

(b)

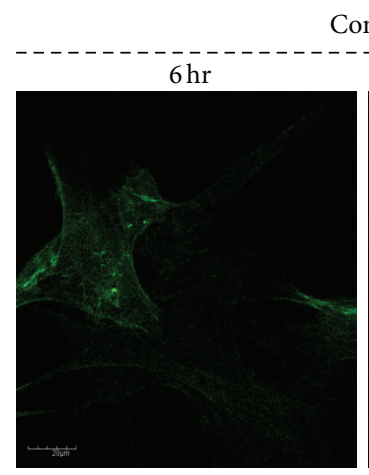

Con
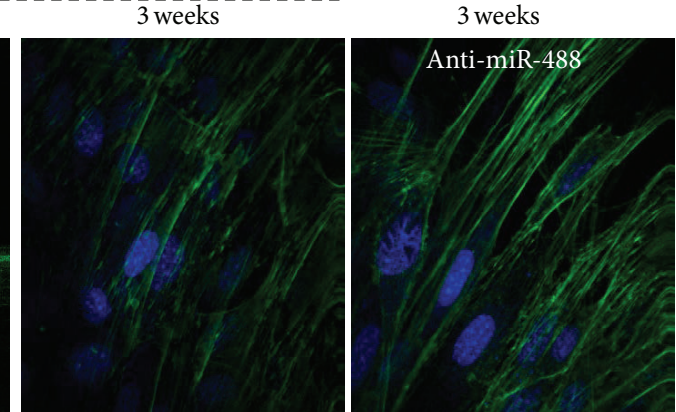

(c)

FIGURE 1: Induction of miR-488 involved in osteoblastic differentiation of MC3T3-E1 cells grown on culture dish. (a) The expression of miR488 was measured using real-time PCR. Alizarin red S stain was used to monitor the mineralization of ECM (inserted photography). Cells were treated with PNA-based ASOs against miR-488 (anti-miR-488) or a scrambled PNA-based ASO (Con). (b) The expression of ALP was measured using real-time PCR. RQ of control culture was used as a control to measure fold change. (c) Cells were immunostained for F-actin with Alexa488-phalloidin. The data shown are representative of at least four independent experiments. The mean is plotted and the error bars represent 95\% CI (lower/upper limit). ${ }^{*} P<0.005$.

the potential involvement of miR-488 in the osteoblastic differentiation of MC3T3-E1 cells, we suppressed miR-488 with PNA-based ASOs. MC3T3-E1 cells were treated with $200 \mathrm{nM}$ of the anti-miR-488 inhibitor for two days, and the mRNA expression of $A L P$ was determined by realtime PCR. The expression of $A L P$ was elevated following treatment of cells with the miR-488 inhibitor (Figure 1(b)). These data suggest that miR-488 may negatively regulate the differentiation of osteoblasts.

Cell adhesion is a fundamental process that directly affects cell proliferation, migration, and differentiation and is involved in many biological behaviors, including the tissue integration of biomaterials [21]. The adhesion of osteoblasts to the implant material surface is essential for the success of any implant that requires osteointegration. It has been suggested that bone cells may produce stress fibers to maintain their desired morphology in the face of chronic applied tension. Since the fate of osteoblast differentiation may be determined by cell shapes in vitro, we performed morphological analysis of MC3T3-E1 cells. We found that the stress fiber density was higher in cells treated for two days with the miR-488 inhibitor compared to cells treated with the scrambled control (Figure 1(c)). A recent study suggested that RhoA, which is known to affect the integrity of actin stress fibers, modulates the function and survival of osteoblasts [22]. Thus, the ability of the miR-488 inhibitor to intensify the density of stress fibers could suggest that miR-488 is functionally relevant in osteoblastic MC3T3-E1 cells.

We generated self-assembled, amorphous, heat-treated, crystallized anatase-phase $\mathrm{TiO}_{2}$ nanotubes by anodizing $\mathrm{Ti}$ sheets in a phosphate-fluoride electrolyte at $20 \mathrm{~V}$ with four different diameters $(30,50,70$, and $100 \mathrm{~nm})$. Upon their initial formation, $\mathrm{TiO}_{2}$ nanotubes typically have an amorphous structure; thereafter, the anatase phase was produced by annealing in air at $500^{\circ} \mathrm{C}$ for $2 \mathrm{~h}$. MC3T3-E1 cells were induced to differentiate by incubation with ascorbic acid and 2-glycerophosphate and then placed on $\mathrm{TiO}_{2}$ nanotubes or culture dishes. Previously, Barthelemi et al. [15] demonstrated 

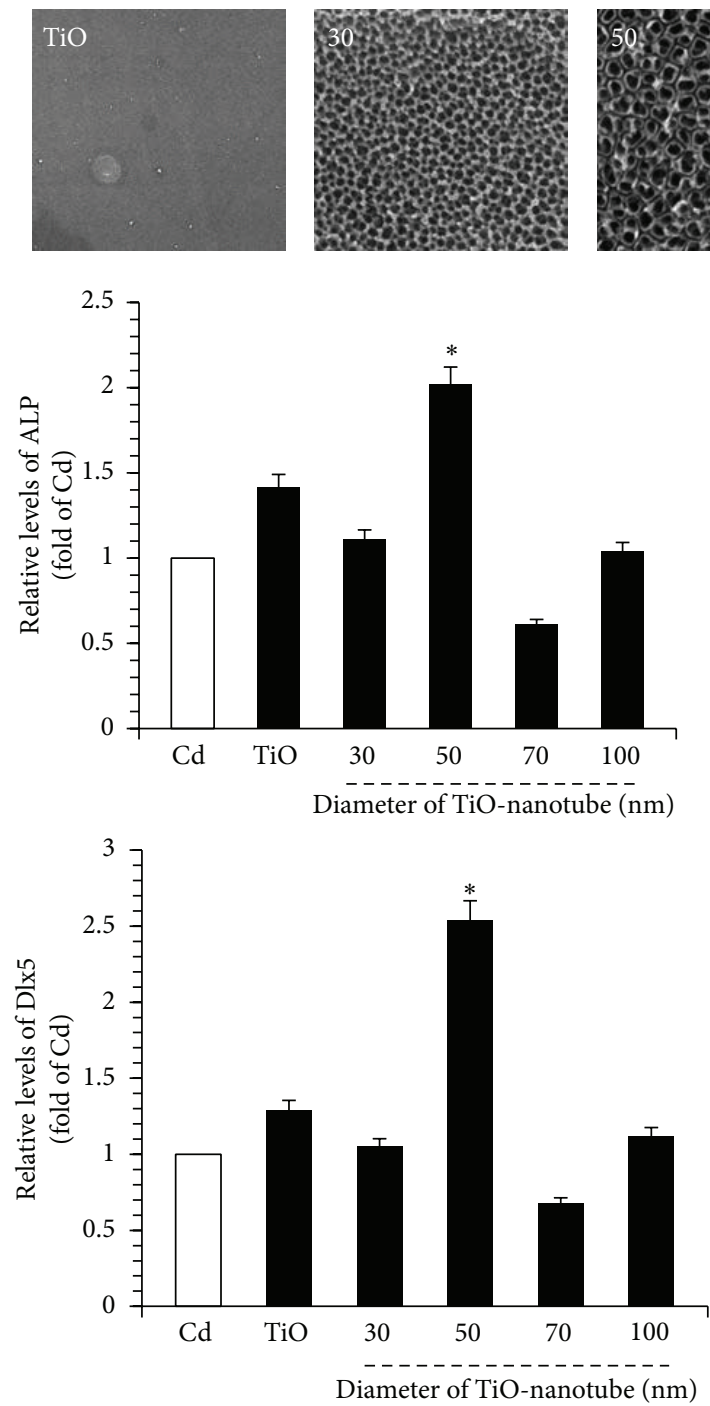
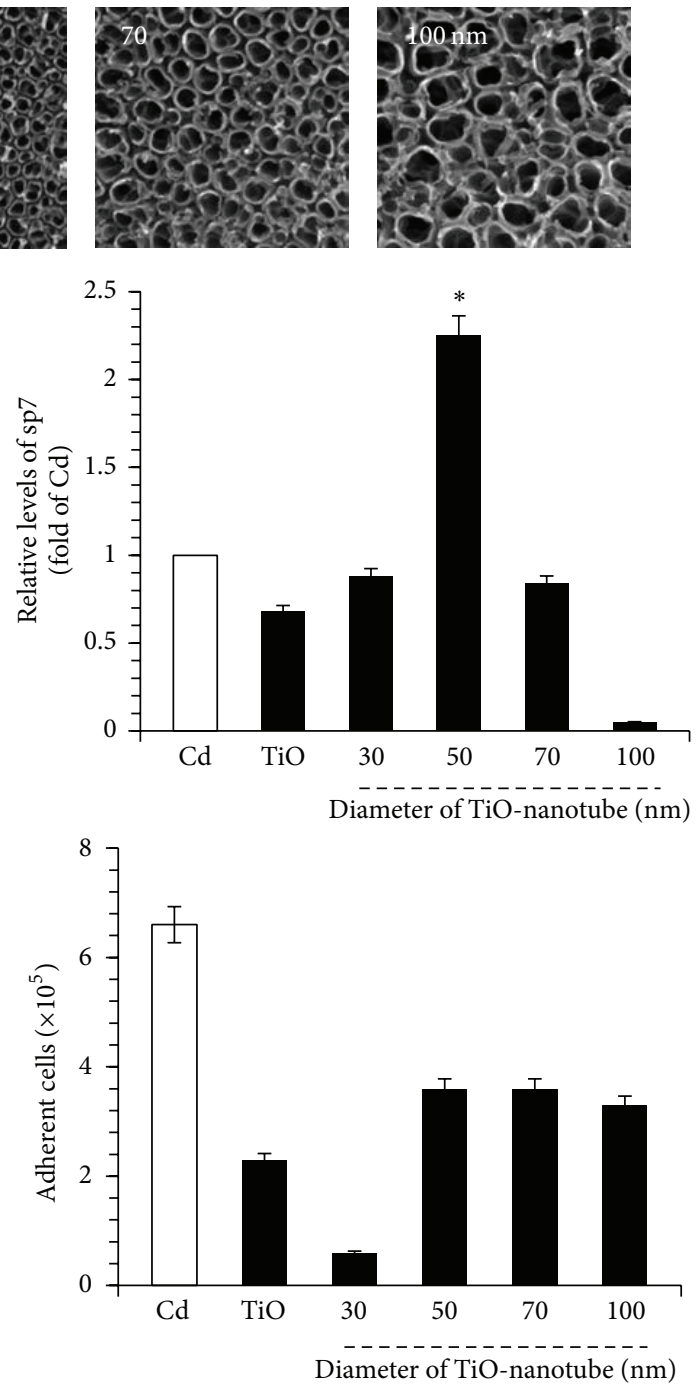

(a)
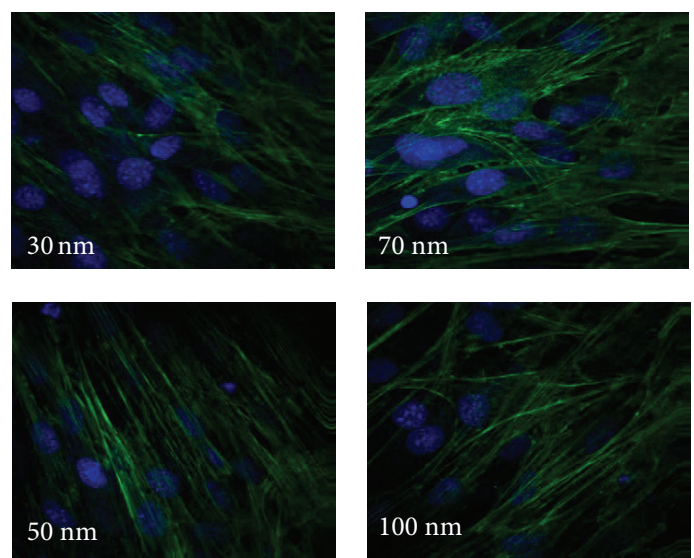

(b)

FIGURE 2: Culture on a $\mathrm{TiO}_{2}$ nanotube surface affects osteoblastic differentiation of MC3T3-E1 cells. MC3T3-E1 cells were cultured on titanium oxide nanotube having various diameters $\left(30,50,70\right.$, and $100 \mathrm{~nm}$ ), titanium oxide $\left(\mathrm{TiO}_{2}\right)$, or culture dish (Cd). (a) The expression of $A L P$, sp7, and Dlx5 was measured using real-time PCR and cell adhesion was assayed at day 2. RQ of cells on culture dish (Cd) was used as a control to measure fold change. (b) Cells were immunostained for F-actin with Alexa488-phalloidin at day 2. Representative data is shown $(n=4)$. The mean is plotted and the error bars represent $95 \%$ CI (lower/upper limit). ${ }^{*} P<0.005$. 


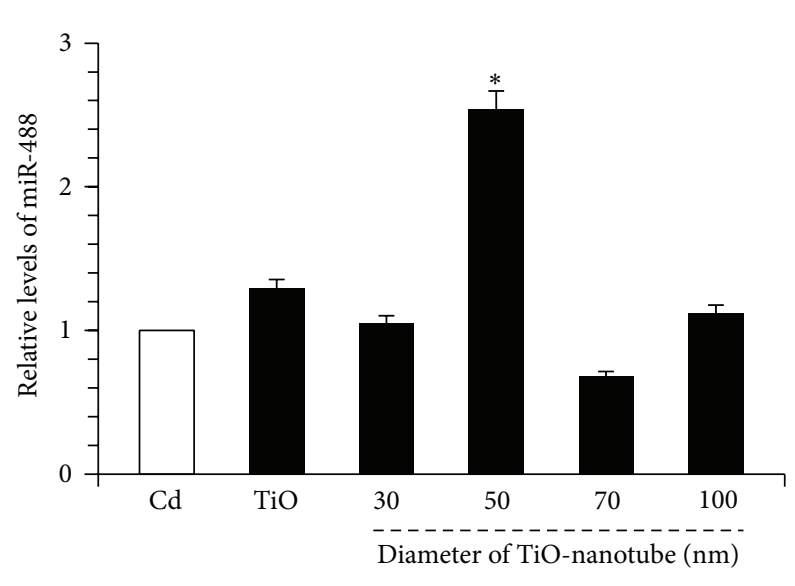

(a)

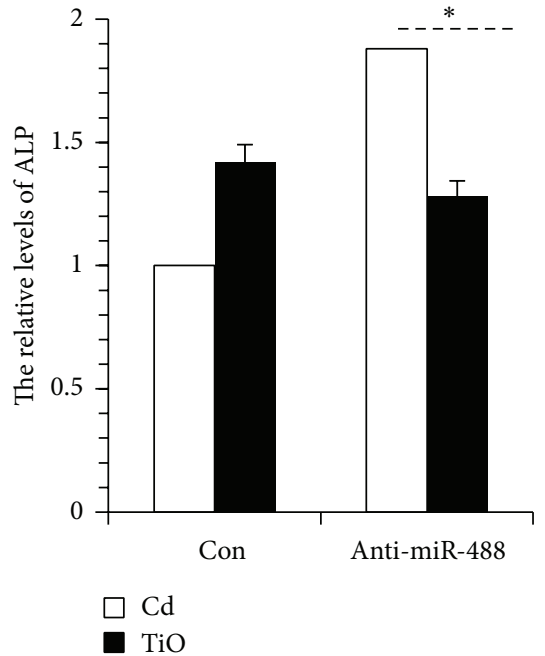

(b)

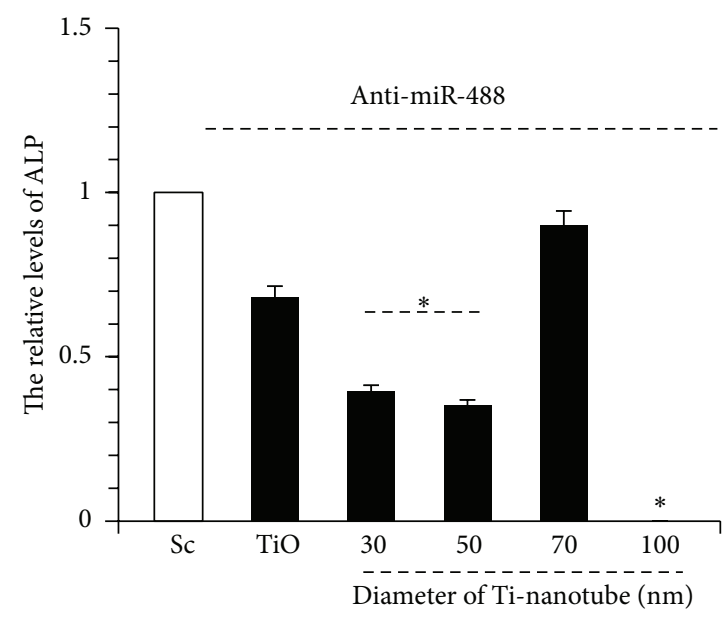

$\square \mathrm{Cd}$

- $\mathrm{TiO}$

(c)

FIGURE 3: miR-488 involved in osteoblastic differentiation of MC3T3-E1 cells on $\mathrm{TiO}_{2}$ nanotube surface. (a) MC3T3-E1 cells were cultured on titanium oxide nanotube having various diameters $(30,50,70$, and $100 \mathrm{~nm})$, titanium oxide $\left(\mathrm{TiO}_{2}\right)$, or culture dish $(\mathrm{Cd})$. The expression of miR-488 was measured at day 2. RQ of cells on culture dish (Cd) was used as a control to measure fold change. (b) MC3T3-E1 cells were cultured with antisense oligonucleotides of miR-488 (anti-miR-488) or a scrambled PNA-based ASO (Con). ALP expression was measured using real-time PCR and cell adhesion was assayed. RQ of control cells on culture dish (Cd) was used as a control to measure fold change. (c) MC3T3-E1 cells were cultured on titanium oxide nanotube having various diameters (30,50, 70, and $100 \mathrm{~nm}$ ), titanium oxide $\left(\mathrm{TiO}_{2}\right)$, or culture dish $(\mathrm{Cd})$ and treated with antisense oligonucleotides of miR-488 (anti-miR-488) or a scrambled PNA-based ASO (Sc). ALP expression was measured using real-time PCR. RQ of cells treated with Sc was used as a control to measure fold change. Representative data is shown $(n=4)$. The mean is plotted and the error bars represent 95\% CI (lower/upper limit). ${ }^{*} P<0.005$.

that a $\mathrm{TiO}_{2}$ nanotube layer (70 nm diameter) significantly enhanced osteogenesis-related gene expression, bone implant contact, and bone deposition on pure titanium implants, indicating that $70 \mathrm{~nm}$ diameter nanotubes are the optimum size for osseointegration. Here, we found that the expression levels of the osteoblast-differentiation-related transcription factor-encoding genes, $A L P, s p 7$, and $D l x 5$, were significantly increased on $\mathrm{TiO}_{2}$ nanotubes compared to culture dishes; these levels peaked in cells grown on $50 \mathrm{~nm}$ nanotubes and then decreased slightly with increasing tube diameter (Figure 2(a)). The density of stress fibers was also highest in cells grown on $50 \mathrm{~nm}$ nanotubes (Figure 2(b)). The adhesion of cells was not affected by the nanotube diameter (data not shown).

The expression level of miR-488 was significantly higher in cells grown on $50 \mathrm{~nm}$ nanotubes (but not those of 


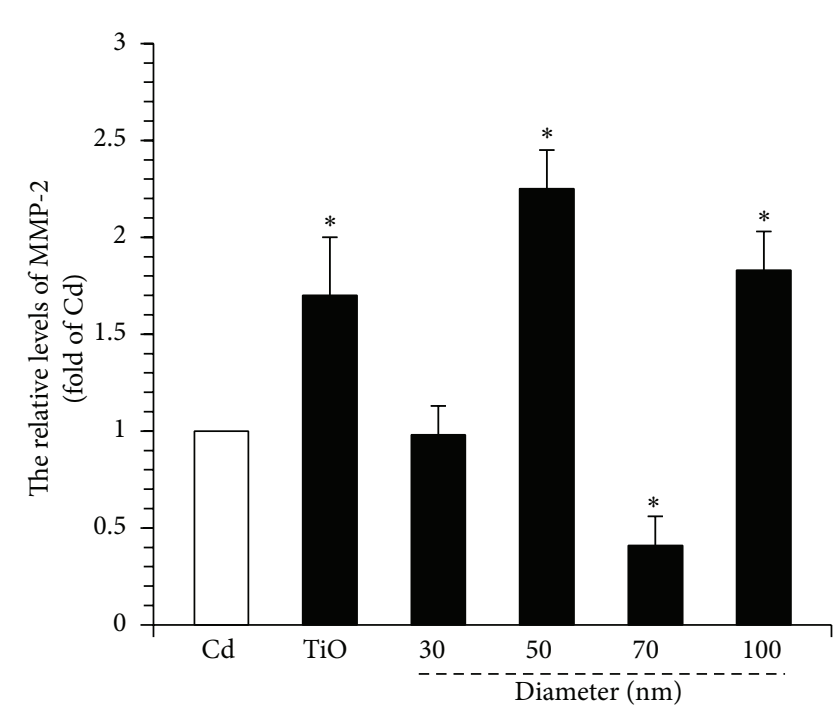

(a)

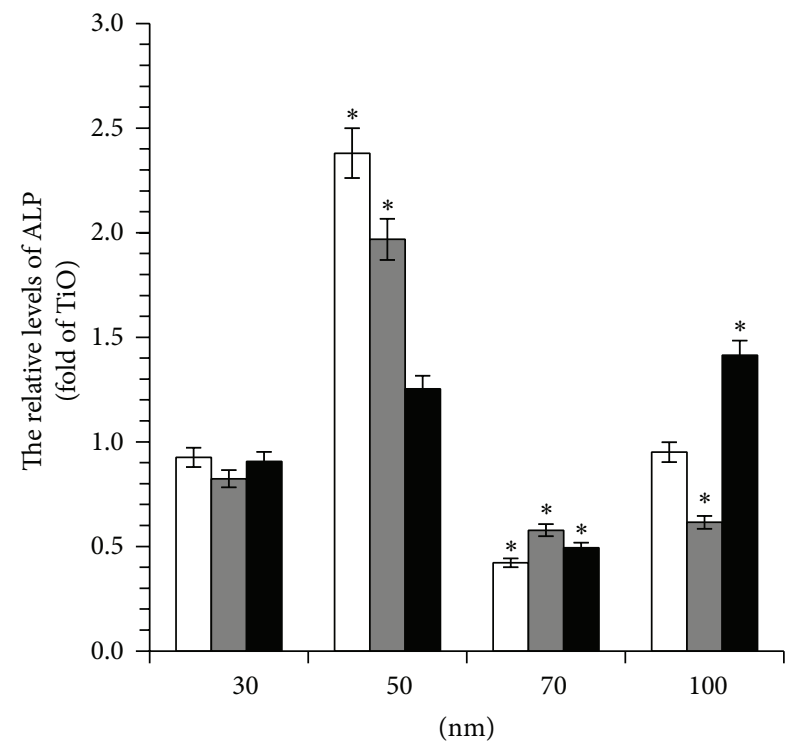

$\square$ Control

Bafilomycin A1

GM6001

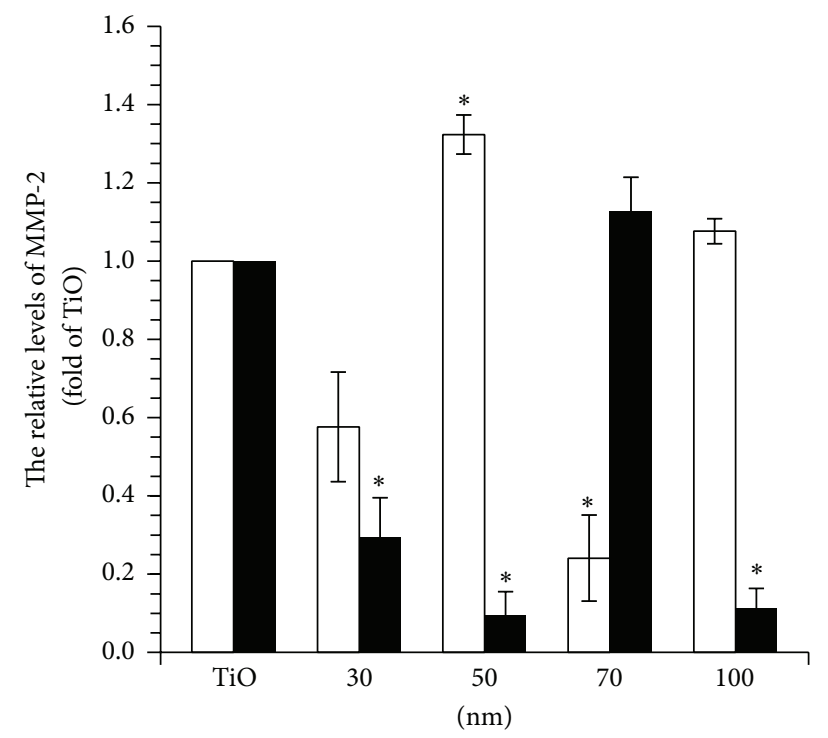

$\square$ Con

Anti-miR-488

(c)

FIGURE 4: MMP-2 modulation by miR-448 affects osteoblastic differentiation of MC3T3-E1 cells on $\mathrm{TiO}_{2}$ nanotube surface. (a) MC3T3-E1 cells were cultured on titanium oxide nanotube having various diameters $(30,50,70$, and $100 \mathrm{~nm})$, titanium oxide $\left(\mathrm{TiO}_{2}\right)$, or culture dish $(\mathrm{Cd})$ and the expression of MMP-2 was measured using real-time PCR. RQ of cells on culture dish (Cd) was used as a control to measure fold change. (b) MC3T3-E1 cells were treated with bafilomycin A1 or GM6001 and the expression of ALP was measured using real-time PCR. RQ of cells on flat titanium oxide was used as a control to measure fold change. (c) MC3T3-E1 cells were cultured on titanium nanotube having various diameters $(30,50,70$, and $100 \mathrm{~nm}$ ) and treated with antisense oligonucleotides of miR-488 (anti-miR-488) or a scrambled PNA-based ASO (Con). Expression of MMP-2 was measured. RQ of cells on flat titanium oxide was used as a control to measure fold change. Representative data is shown $(n=4)$. The mean is plotted and the error bars represent $95 \%$ CI (lower/upper limit). ${ }^{*} P<0.005$. 
other diameters) versus those grown on culture dishes (Figure 3(a)). Interestingly, cells treated with the anti-miR488 oligonucleotide inhibitor acted differently on plastic polypyrene versus $\mathrm{TiO}_{2}$ surfaces: the inhibitor induced $A L P$ transcription in cells grown on culture dishes but slightly reduced $A L P$ transcription in cells grown on $\mathrm{TiO}_{2}$ (Figure 3(b)). Notably, the anti-miR-488 inhibitor suppressed the transcription of $A L P$ to the greatest degree in cells plated on $50 \mathrm{~nm} \mathrm{TiO}_{2}$ nanotubes (Figure 3(c)). These data suggest that the nature of the substratum could affect the internal environment and modulate the differential capacity of osteoblasts.

Under normal physiological conditions, osteoblasts are able to degrade the organic material of the bone matrix. Osteoblast precursors express MMP-2, $-8,-13$, and -14 , which may be involved in the degradation of bone matrix materials (e.g., type I collagen) [23]. Consistent with this observation, we found that when the miR-488 inhibitor induced the differentiation of MC3T3-E1 cells (Figure 1(a)), the induction of MMP-2 was also increased (Figure 4(a)). However, material properties such as surface chemistry and surface topography are well known to affect cellular behavior, thereby affecting cell fate [24]. Here, we found that, among cells cultured on $\mathrm{TiO}_{2}$ surfaces of various diameters, MMP2 expression and $A L P$ activity were significantly increased on $50 \mathrm{~nm}$ nanotubes (Figure 2(a)). In addition, we found that modulation of MMP- 2 activity could affect $A L P$ activity in our system. Bafilomycin Al is known to increase the activation of proMMP-2 by the abundance of active MT1MMP on the cell surface $[25,26]$. Here, we found that bafilomycin Al treatment increased ALP activity in cells grown on $50 \mathrm{~nm}$ nanotubes. In contrast, treatment of cells with $3 \mu \mathrm{M}$ GM6001, which has been shown to inhibit MMP2 activity $[27,28]$, decreased $A L P$ activity among cells grown on various-diameter nanotubes (Figure $4(\mathrm{~b})$ ). These data support the notion that material properties can affect cellular behaviors and responses. Interestingly, the miR- 488 inhibitor had differential effects on MMP-2 expression depending on the growth substrate: it inhibited MMP-2 expression in cells grown on $50 \mathrm{~nm}$ nanotubes but significantly enhanced MMP2 expression in cells grown on $70 \mathrm{~nm}$ nanotubes (Figure 4(c)).

These data collectively suggest that biophysical stimuli and environmental conditions could be important factors in the clinical use of $\mathrm{TiO}_{2}$ nanotubes. Recent studies have shown that miR-488 is involved in several diseases, including prostate cancer [29], lung cancer [23], and panic disorder [30]. For clinical applications of $\mathrm{TiO}_{2}$ nanotubes, it may therefore be necessary to investigate the relationship between the desired implant material and certain patient characteristics (e.g., miR-488 levels).

\section{Conclusions}

One of the biggest challenges in developing implants with improved longevity and minimum failure is the control of successful osseointegration. Osteoblasts are critical for the osseointegration of endosseous implants because they synthesize/produce ECM and control its mineralization. Here, we explored differences in the osteogenic responses of cells grown on $30 \mathrm{~nm}, 50 \mathrm{~nm}, 70 \mathrm{~nm}$, and $100 \mathrm{~nm} \mathrm{TiO}_{2}$ nanotubes. We found that the $50 \mathrm{~nm}$ diameter yielded the best osteoblast differentiation (as assessed by $A L P$ expression) and could therefore be optimal for implant use. However, we also obtained evidence suggesting that biophysical stimuli and endogenous environmental conditions could also critically affect the behavior of osteoblasts. We found that modulation of miR-488 had different effects on cells depending on their growth substrate (i.e., culture dishes or $\mathrm{TiO}_{2}$ nanotubes of various diameters). These findings suggest that we need to fully understand the interactions of endogenous biological parameters (e.g., miRNAs) and the physicochemical properties of $\mathrm{Ti}$ nanotubes in order to optimize the clinical application of such materials in implant medicine.

\section{Abbreviations}

$\begin{array}{ll}\text { ALP: } & \text { Alkaline phosphatase } \\ \text { MMP-2: } & \text { Matrix metalloprotease-2 } \\ \text { miRNA, miR: } & \text { MicroRNA } \\ \mathrm{TiO}_{2}: & \text { Titanium oxide } \\ \text { ECM: } & \text { Extracellular matrix. }\end{array}$

\section{Conflict of Interests}

The authors declare that there is no conflict of interests regarding the publication of this paper.

\section{Authors' Contribution}

Yeon-Ho Kang and Bohm Choi contributed equally in this study.

\section{Acknowledgments}

This study was supported by a Grant fromthe Korean Health Technology R\&D Project (Ministry of Health \& Welfare, Republic of Korea; A120152) and the National Research Foundation of Korea (NRF) Grant funded by the Korean government (MSIP) [2011-0030130 and 2013R1A1A2011999]. The funders did not play any role in the study design, data collection, data analysis, decision to publish, or preparation of the paper.

\section{References}

[1] M. Lai, K. Cai, L. Zhao, X. Chen, Y. Hou, and Z. Yang, "Surface functionalization of $\mathrm{TiO}_{2}$ nanotubes with bone morphogenetic protein 2 and its synergistic effect on the differentiation of mesenchymal stem cells," Biomacromolecules, vol. 12, no. 4, pp. 1097-1105, 2011.

[2] T. Miyauchi, M. Yamada, A. Yamamoto et al., "The enhanced characteristics of osteoblast adhesion to photofunctionalized nanoscale $\mathrm{TiO}_{2}$ layers on biomaterials surfaces," Biomaterials, vol. 31, no. 14, pp. 3827-3839, 2010.

[3] R. Junker, A. Dimakis, M. Thoneick, and J. A. Jansen, "Effects of implant surface coatings and composition on bone integration: 
a systematic review," Clinical Oral Implants Research, vol. 20, supplement s4, pp. 185-206, 2009.

[4] J. Park, S. Bauer, P. Schmuki, and K. Von Der Mark, "Narrow window in nanoscale dependent activation of endothelial cell growth and differentiation on $\mathrm{TiO}_{2}$ nanotube surfaces," Nano Letters, vol. 9, no. 9, pp. 3157-3164, 2009.

[5] T. J. Webster, R. W. Siegel, and R. Bizios, "Osteoblast adhesion on nanophase ceramics," Biomaterials, vol. 20, no. 13, pp. 12211227, 1999.

[6] J. G. Doench, C. P. Petersen, and P. A. Sharp, "siRNAs can function as miRNAs," Genes and Development, vol. 17, no. 4, pp. 438-442, 2003.

[7] Y. K. Kim, L. Furic, L. DesGroseillers, and L. E. Maquat, "Mammalian Staufen1 recruits Upf1 to specific mRNA 3'UTRs so as to elicit mRNA decay," Cell, vol. 120, no. 2, pp. 195-208, 2005.

[8] K. Kapinas and A. M. Delany, "MicroRNA biogenesis and regulation of bone remodeling," Arthritis Research and Therapy, vol. 13, no. 3, article 220, 2011.

[9] Z. Q. Wang, Y. Q. Lu, and J. X. Han, "MicroRNAs: important mediators of ossification," Chinese Medical Journal (English Edition), vol. 125, pp. 4111-4116, 2012.

[10] H. Inose, H. Ochi, A. Kimura et al., "A microRNA regulatory mechanism of osteoblast differentiation," Proceedings of the National Academy of Sciences of the United States of America, vol. 106, no. 49, pp. 20794-20799, 2009.

[11] T. Itoh, Y. Nozawa, and Y. Akao, "MicroRNA-141 and -200a are involved in bone morphogenetic protein-2-induced mouse preosteoblast differentiation by targeting distal-less homeobox 5," Journal of Biological Chemistry, vol. 284, no. 29, pp. 19272-19279, 2009.

[12] Z. Li, M. Q. Hassan, M. Jafferji et al., "Biological functions of miR-29b contribute to positive regulation of osteoblast differentiation," Journal of Biological Chemistry, vol. 284, no. 23, pp. 15676-15684, 2009.

[13] H. Li, H. Xie, W. Liu et al., "A novel microRNA targeting HDAC5 regulates osteoblast differentiation in mice and contributes to primary osteoporosis in humans," Journal of Clinical Investigation, vol. 119, no. 12, pp. 3666-3677, 2009.

[14] J. Song, D. Kim, and E.-J. Jin, "MicroRNA-488 suppresses cell migration through modulation of the focal adhesion activity during chondrogenic differentiation of chick limb mesenchymal cells," Cell Biology International, vol. 35, no. 2, pp. 179-185, 2011.

[15] S. Barthelemi, J. Robinet, R. Garnotel et al., "Mechanical forcesinduced human osteoblasts differentiation involves MMP2/MMP-13/MT1-MMP proteolytic cascade," Journal of Cellular Biochemistry, vol. 113, no. 3, pp. 760-772, 2012.

[16] G. S. Stein, J. B. Lian, and T. A. Owen, "Relationship of cell growth to the regulation of tissue-specific gene expression during osteoblast differentiation," FASEB Journal, vol. 4, no. 13, pp. 3111-3123, 1990.

[17] S. Gronthos, A. C. W. Zannettino, S. E. Graves, S. Ohta, S. J. Hay, and P. J. Simmons, "Differential cell surface expression of the STRO-1 and alkaline phosphatase antigens on discrete developmental stages in primary cultures of human bone cells," Journal of Bone and Mineral Research, vol. 14, no. 1, pp. 47-56, 1999.

[18] S. Dong, B. Yang, H. Guo, and F. Kang, "MicroRNAs regulate osteogenesis and chondrogenesis," Biochemical and Biophysical Research Communications, vol. 418, no. 4, pp. 587-591, 2012.
[19] M. Q. Hassan, J. A. R. Gordon, M. M. Beloti et al., "A network connecting Runx2, SATB2, and the miR-23a 27a 24-2 cluster regulates the osteoblast differentiation program," Proceedings of the National Academy of Sciences of the United States of America, vol. 107, no. 46, pp. 19879-19884, 2010.

[20] Z. Li, M. Q. Hassan, S. Volinia et al., "A microRNA signature for a BMP2-induced osteoblast lineage commitment program," Proceedings of the National Academy of Sciences of the United States of America, vol. 105, no. 37, pp. 13906-13911, 2008.

[21] M. Mizuno, H. Kawamura, N. Takei, and H. Nawa, "The anthraquinone derivative Emodin ameliorates neurobehavioral deficits of a rodent model for schizophrenia," Journal of Neural Transmission, vol. 115, no. 3, pp. 521-530, 2008.

[22] M. Dettin, M. T. Conconi, R. Gambaretto et al., "Effect of synthetic peptides on osteoblast adhesion," Biomaterials, vol. 26, no. 22, pp. 4507-4515, 2005.

[23] N. H. Kazmers, S. A. Ma, T. Yoshida, and P. H. Stern, "Rho GTPase signaling and PTH 3-34, but not PTH 1-34, maintain the actin cytoskeleton and antagonize bisphosphonate effects in mouse osteoblastic MC3T3-E1 cells," Bone, vol. 45, no. 1, pp. 5260, 2009.

[24] K. Anselme, P. Linez, M. Bigerelle et al., "The relative influence of the topography and chemistry of TiAl6V4 surfaces on osteoblastic cell behaviour," Biomaterials, vol. 21, no. 15, pp. 1567-1577, 2000.

[25] S. Hernandez-Barrantes, M. Toth, M. M. Bernardo et al., "Binding of active $(57 \mathrm{kDa})$ membrane type 1-matrix metalloproteinase (MT1-MMP) to tissue inhibitor of metalloproteinase (TIMP)-2 regulates MT1-MMP processing and pro-MMP-2 activation," Journal of Biological Chemistry, vol. 275, no. 16, pp. 12080-12089, 2000.

[26] E. Maquoi, A. Noël, F. Frankenne, H. Angliker, G. Murphy, and J.-M. Foidart, "Inhibition of matrix metalloproteinase 2 maturation and HT1080 invasiveness by a synthetic furin inhibitor," FEBS Letters, vol. 424, no. 3, pp. 262-266, 1998.

[27] W. Zhou, B. O. Ibe, and J. U. Raj, "Platelet-activating factor induces ovine fetal pulmonary venous smooth muscle cell proliferation: role of epidermal growth factor receptor transactivation," American Journal of Physiology-Heart and Circulatory Physiology, vol. 292, no. 6, pp. H2773-H2781, 2007.

[28] Y. Macotela, M. B. Aguilar, J. Guzmán-Morales et al., "Matrix metalloproteases from chondrocytes generate an antiangiogenic $16 \mathrm{kDa}$ prolactin," Journal of Cell Science, vol. 119, no. 9, pp. 1790-1800, 2006.

[29] K. Sikand, J. E. Slaibi, R. Singh, S. D. Slane, and G. C. Shukla, "MiR 488* inhibits androgen receptor expression in prostate carcinoma cells," International Journal of Cancer, vol. 129, no. 4, pp. 810-819, 2011.

[30] M. Muiños-Gimeno, Y. Espinosa-Parrilla, M. Guidi et al., "Human microRNAs miR-22, miR-138-2, miR-148a, and miR488 are associated with panic disorder and regulate several anxiety candidate genes and related pathways," Biological Psychiatry, vol. 69 , no. 6 , pp. 526-533, 2011. 

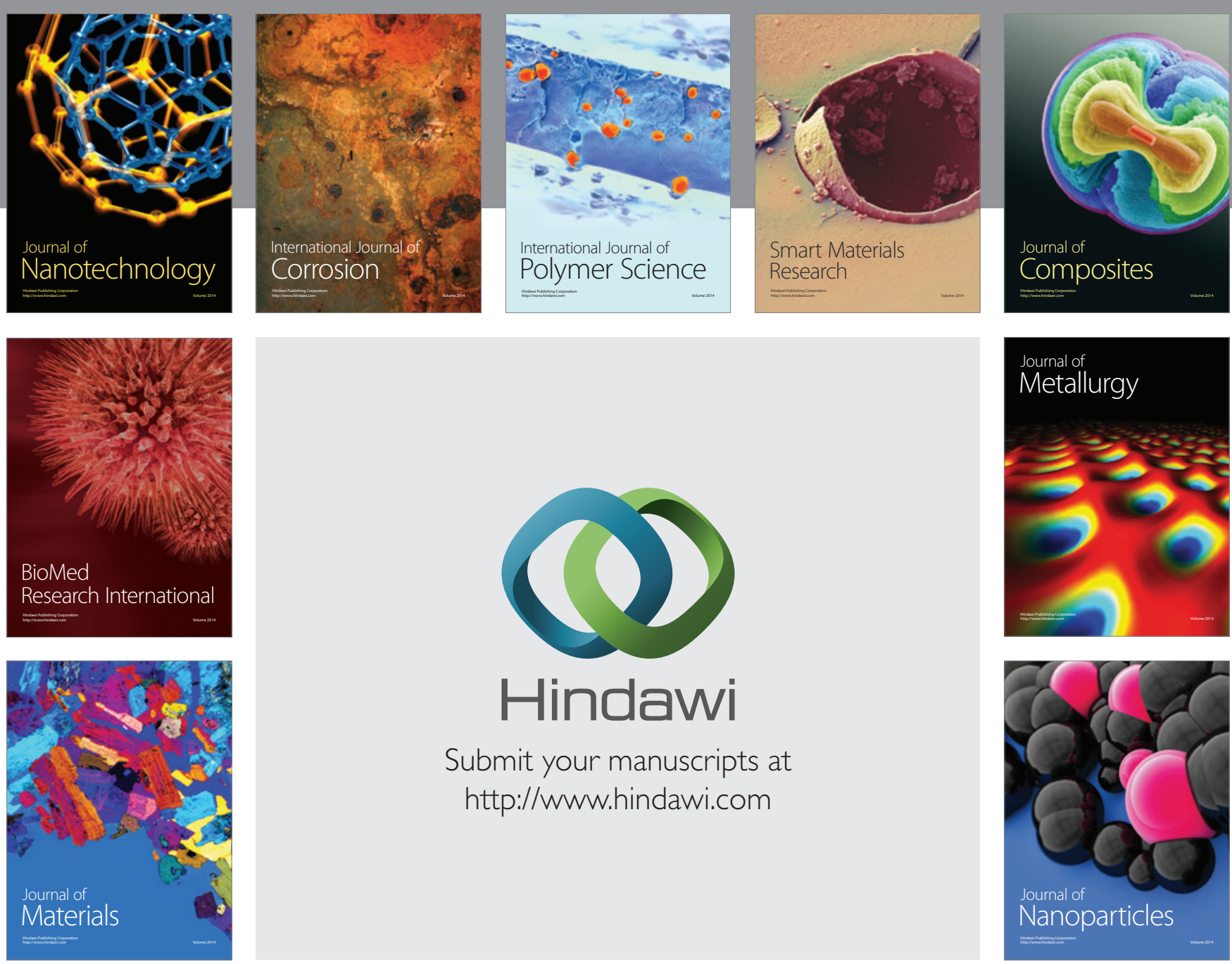

Submit your manuscripts at http://www.hindawi.com
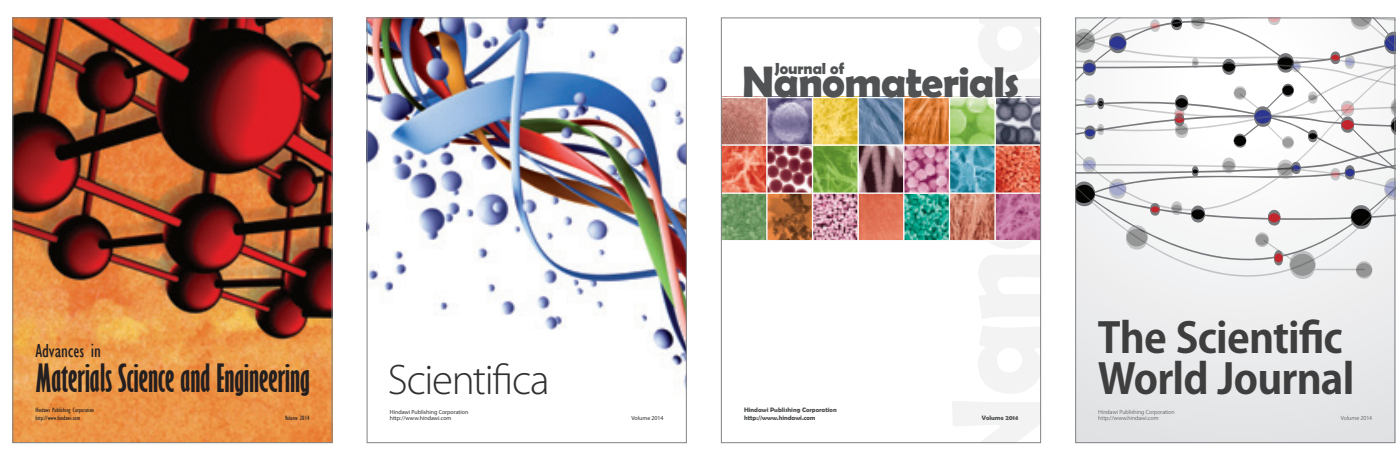

\section{The Scientific World Journal}
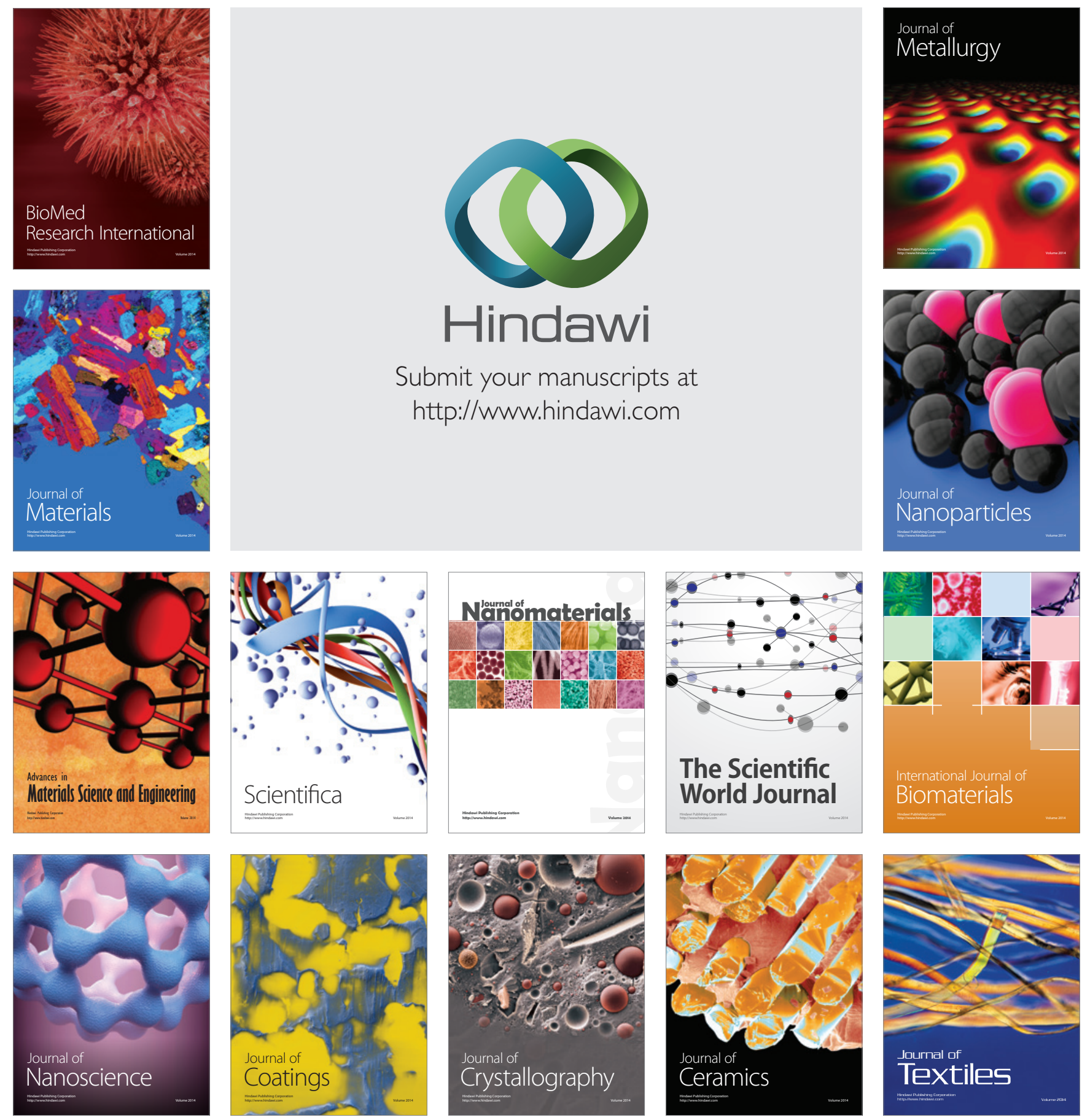